\title{
Conceptual Provisions of the Adaptability of Microfinance Organizations for Entrepreneurship in the Context of the Limited Economy of Russia
}

\author{
Irina Misanova ${ }^{1,2, *}$, Nadezhda Gusareva ${ }^{1}$, Dmitriy Tarasov, ${ }^{3}$ Galina Andriuschenko ${ }^{1}$, and \\ Larisa Sorokina ${ }^{4}$ \\ ${ }^{1}$ Gubkin Russian State University of Oil and Gas, 119991 Moscow, Russia \\ ${ }^{2}$ Russian University of Transport, 127994 Moscow, Russia \\ ${ }^{3}$ Financial University under the Government of the Russian Federation, 125993 Moscow, Russia \\ ${ }^{4}$ Peoples' Friendship University of Russia, 117198 Moscow, Russia
}

\begin{abstract}
Changes in the world order, political and economic events of modern times reveal relevant aspects for the development of financial instruments. The interest shown in microfinance organizations is determined by the socio-economic realities of the country: the urgent need to revive entrepreneurship, internal competition, adaptation to the market in a limited economy. In this connection, the considered conceptual provisions are aimed at prompt response to deviations from the normal activities of entrepreneurship. There was a need for changes in international and national investment policy on the way to a real network development methodology: from a coordinated structure of relations to more and more legally binding decisions of all participating countries. Investments are dispersed. In this regard, the development of methodological aspects, the design of a roadmap, taking into account recommendations for the formation of an operating model and a business model within the framework of MFO activities, seems to be very relevant.
\end{abstract}

\section{Introduction}

In a market economy, there is an urgent need for the segmentation of the financial market and the separation of microfinance organizations (MFOs) into a special segment. This is due to the specifics of their activities - providing small and medium-sized enterprises (SMEs) with microloans on the basis of budget funds. MFOs are subjects of a certain type of professional activity.

Thus, at the present stage of their development, the mission of state MFOs is as follows:

- Attracting SMEs to the use of borrowed funds.

- Expanding the funnel of entry for SMEs: increasing the availability of lending through not only cheap loans for entrepreneurs, but also by simplifying the

\footnotetext{
*Corresponding author: kino-rodina@mail.ru
} 
procedure for providing the microcredits, individualizing interaction with borrowers and accompanying them throughout the entire loan period.

- Development of competencies related to financial transactions through the organization of training entrepreneurs in financial literacy and the development of skills for effective business management. "Upon reaching a certain level of competence, the SME entity can move to the contour of traditional banking services" [1].

- Formation of a financial culture of entrepreneurs with a focus on openness, transparency, and reliability of the entire financial reporting system.

- Timely allocation of financing to newly established companies already at the stage of business idea, which will contribute to the expansion of the SME sector in the regions.

- Strengthening the presence of microfinance organizations in regions that are not of commercial interest to the banks. These are hard-to-reach areas, sparsely populated settlements, remote areas, monotowns.

- The introduction of modern digital technologies in the activities of MFOs, which ensures the implementation of the regional digitalization program and "participation in regional digital transformation" [2, 3].

All of these activities reflect an integrated approach to the development of the MFO system with state participation. The conducted continuous diagnostics of microfinance organizations operating in all constituent entities of the Russian Federation makes it possible to determine systemic problems of the functioning of the formed business models (customers, products, promotion channels), as well as to assess the effectiveness of operating models (key business processes, productivity, risks). The developed recommendations on the functioning of state MFOs are aimed at ensuring conditions for the further development of the system of microfinance services for business structures, as well as monitoring the activities of regional MFOs and monitoring the effectiveness of their state support.

Based on the above, it becomes necessary to conduct a comprehensive assessment of the adaptation of state MFOs to new economic constraints in order to adjust the management impact and update the developed Concept for the development of the MFO system.

\section{Materials and methods}

The methodological basis for a comprehensive assessment of the adaptation of MFOs to new economic constraints is the provisions of the developed Concept for the development of the MFO system, proposed by the authors.

The unified approach to the development of state microfinance organizations in the field of entrepreneurship, reflected in the Concept, ensures the implementation of state policy in the development of the MFO system.

The objectives of the Concept are as follows:

- Formation of the methodological foundations for the functioning of the existing MFO system in the Russian Federation (its goals, objectives, development foundations).

- Systematization and generalization of the experience of MFO functioning in formalized recommendations.

- Assistance in improving the financial stability of the MFO system.

- Counteracting negative trends and bankruptcy of MFO organizations by preventing a decrease in the value of net assets and promoting an earlier formation of selfsufficiency. 
- Development of uniform principles for taxation of MFOs.

- Development of risk-based management in MFOs.

- Strengthening the financial discipline of MFOs.

- Improving the system of performance indicators of MFOs.

- Development of digital technologies and the formation of an information and analytical infrastructure for MFOs.

- Preventing MFOs from participating in illegal activities related to legalization (laundering) of proceeds from crime and financing of terrorism.

- Creation of regulations for monitoring the activities of MFOs.

- Formulation of requirements and restrictions for monitoring the effectiveness of state support for MFOs.

\section{Results and discussions}

The Concept provides a number of recommendations aimed at improving the activities of MFOs.

To create the conditions for countering risks and reducing uncertainty, the Concept provides for a set of measures aimed at realizing favorable opportunities and more effectively achieving the goals of MFOs [4]. MFO risk management policy is aimed at ensuring asset protection, preventing negative trends in the development of risk events. It is necessary to create a Risk Register, which will significantly increase the manageability and quality of management decision-making in MFOs. The Risk Register will include a list of identified risks and the results of processing information on the risk map for each risk. Responsible for maintaining the Register will be the risk manager, who will analyze the information coming from the departments. Among the documents that are required for effective risk management are the Passports and Risk Maps, the Report on the Risk Management System (prepared for the head of the MFO).

Work with overdue debts is important in the activities of microfinance organizations. In our opinion, when forming the regulations for dealing with overdue debts, it is necessary to:

1. Take the provisions of the basic standard for dealing with overdue debts of SROs and, on its basis, develop internal regulations as a basis.

2. Carry out a reorganization of overdue debt.

3. Develop a Regulation operating with overdue debt under microloan agreements and control over the fulfillment of contractual obligations.

4. In the composition of measures for dealing with overdue debts, it is necessary to include a set of measures aimed at both preventing the occurrence of overdue debts and working with existing overdue debts. Among the preventive measures, we note the measures aimed at normalizing the debtor's financial condition and preventing its deterioration.

An important area of work with the clients is a detailed financial analysis of a potential borrower. This will prevent the issuance of a microloan to a potentially unreliable client who is unable to provide a refund. We consider the experience of MFOs in attracting a personal guarantee of the ultimate beneficiary of a business, transactions with a pledge of personal property with a market value that covers the costs of servicing a loan, a pledge of industrial assets, and an acceptance for debiting funds from a borrower's bank accounts. Good results are obtained by quarterly monitoring of the financial condition of the borrower, which makes it possible to take timely measures (full or partial early repayment) if the situation worsens. This is especially true for unsupported unsecured microloans as particularly risky ones. 
Among the recommendations for working with the representative offices and network agents, we note the importance of following the mechanism of interaction between the agent and the MFO, the sequence of activities in the Regulation for attracting the clients, transferring a package of documents for a microloan to an MFO, providing a microloan to a client, paying for services to an agent.

Agents can be MFos' client attraction representatives. It is recommended to conclude an agreement on cooperation through information exchange of the organization of entrepreneurial activity and state support aimed at the development of SMEs in the region for various target audiences with the stakeholders, including government services, public organizations and higher educational institutions.

Factors that determine the ability of an MFO to meet its obligations are significant. The key quantitative factors are capital adequacy, profitability, liquidity, debt burden, quality of the loan portfolio, diversification of credit risks, and competitive positions.

The key quality factors are business reputation, the quality of corporate governance and business processes. These two significant groups of factors are taken into account when rating the MFOs.

The introduction of the digitalization elements into the business processes of MFOs will significantly expand the organization of remote workplaces, create a unified information space that ensures the activities of MFOs, and contribute to the implementation of the Borrower's Personal Account service. It is proposed to integrate MFOs into the interdepartmental electronic interaction system (IEIS) through a centralized access point represented by the Ministry of Economic Development of the Russian Federation. Modern technologies of using electronic digital signatures, widespread use of mobile applications will improve interaction with the borrower.

To improve MFOs, it is necessary to apply not only the elements of automation and digitalization, but also develop technologies taking into account the use of remote workplaces, as well as create a unified information platform for the implementation of MFO activities (at the stage of creation by the Ministry of Economic Development of the Russian Federation), including the development the use of Borrower's Personal Accounts. Accordingly, it is necessary as follows:

- Organize the connection of MFOs to the interdepartmental electronic interaction system (IEIS) in a single stream of access with the Ministry of Economic Development of the Russian Federation.

- Organize cooperation with the borrower through mobile applications.

- Apply an electronic digital signature.

Considering the above, it should be noted that it is important to create a unified information platform for electronic interaction between economic participants. This platform is also recommended to be used for storing financial information, and when introducing digital technologies for the development of financial services, information, analytical and communication space of all interested parties.

The information resource is aimed at disseminating reliable information about various plans for social and economic development, digital banking guarantees of a distributed ledger, as well as fraudulent schemes, etc. [5-7].

Exploring the classification of MFOs, we note that in order to improve their performance, it is proposed to design a roadmap taking into account the recommendations for the formation of an operating model and a business model within the framework of the MFO's activities.

In order to improve the efficiency of MFOs, it is necessary to introduce representatives to the Supervisory Boards from public and trade union organizations directly related to or related to priority groups of SMEs. 
To minimize the risk in terms of solvency, it is proposed to divide the MFO and the guarantee background into two independent legal entities.

To maintain the client base, it is recommended to determine the acceptable level of debt of the borrower to the tax authorities. And from non-targeted or ineffective use of budget funds, it is necessary to establish the maximum possible amount of funds "on deposits and (or) under agreements to a bank account on a minimum balance on the principle of urgency and payment, at the level of $15 \%$ of the current value of MFO assets. However, an exception should be made for MFOs that received additional capitalization in the reporting period and subsequent to the reporting period "[8].

The informational basis for monitoring the activities of MFOs is "MFO financial statements; management reporting of MFOs; AIS monitoring data; official data of the Central Bank, the Federal State Statistics Service, the results of a survey of MFOs. The reporting period is a quarter and a year" [8].

Evaluation of the mechanism of MFO activity examines three blocks (index component) of efficiency:

- Economic.

- Budgetary.

- Social.

The economic efficiency of MFOs is nothing more than the result of an integral assessment of their financial stability and the ability to interact, expand and maintain the balance of their assets and liabilities in an unstable external and internal environment.

International experience shows that rating systems should be used to determine the efficiency of the economic activity of MFOs, such as: "PEARLS; ACCION Camel; GIRAFE; Microrate; MicroBanking Bulletin; MicroBanking Standards Project; The Philippine Coalition; CGAP Microfinance Rating and Assessment Fund "[8]. The listed rating systems are also used to determine the financial condition of MFOs.

In general, five main sub-indices are examined for rating MFOs:

- General financial condition.

- Portfolio quality.

- Competitive position.

- Quality of business processes.

- Business reputation [8].

If we consider the state policy in terms of regulating the activities of MFOs, then the efficiency for the budget is relative and preserves the unity of the MFO's activities with the main indicators adopted in the national project "Small and Medium Enterprises and Support for Individual Entrepreneurial Initiatives" [9]. The purpose of the assessment for this component is to identify trends in the development of key indicators, taking into account the requirements of national projects in relation to MFOs.

Social efficiency is characterized by the achieved social effect from the activities of MFOs, which is expressed by the coverage of the portfolio of priority groups in the field of lending to small and medium-sized businesses. The purpose of the assessment for this component is to identify the trends in the development of indicators for groups of borrowers designated as priority ones, in accordance with the requirements of national projects in relation to MFOs.

The mechanism for monitoring the financial condition of MFOs should be implemented on the basis of assessing the creditworthiness of MFOs according to the selected list of economic efficiency indicators [7, 10].

In the event of a deterioration in the financial condition of MFOs, a financial recovery plan is drawn up, the purpose of which is to restore the values of key performance indicators of MFOs to the recommended values. It is recommended to draw up a plan for 3 years with details of activities for the first year. If it is impossible to achieve the 
recommended values of indicators, it is advisable to consider the issue of reorganizing the MFO.

In order to effectively manage risks in the activities of MFOs on the basis of an information and analytical approach using modern IT tools, it is proposed to introduce the National Risk Register, which is a systematized collection of information about risk events. The creation of a unified risk database on the blockchain principle will allow machine analysis of any variations in risk situations and the likelihood of their occurrence, thereby providing support for managerial decision-making. The risk register should include information about the risk events that have occurred, actions taken to manage them, methods of controlling and diagnosing MFO activities, as well as the results of risk assessment.

It is important to note that the feasibility of creating a National Risk Register is due to the rather low frequency of risk situations in the activities of individual MFOs, which often speaks only of the hypothetical readiness of MFOs to prevent risk events without controlling and other diagnostic procedures for risk management.

\section{Conclusion}

1. Thus, it should be noted that the need to assess the importance of MFOs in the regional system of support for small and medium-sized businesses is confirmed by the feasibility of implementing a competitive approach to the distribution of budget funds, a comparative analysis of the effectiveness of subsidies in the regional context, as well as an assessment of the consequences when implementing regional support.

2. The feasibility of determining the degree of development of the system of small and medium-sized businesses at the regional level is due to the fact that state support should, first of all, be directed to those constituent entities of the Russian Federation where, for one reason or another, the system of small and medium-sized businesses does not develop or is stagnating.

\section{References}

1. F. Donou-Adonsou, K. Sylwester, Quarterly Review of Economics \& Finance, 64, 44 (2017)

2. N.L. Balamirzoev, N.S. Surakatov, Bulletin of GGNTU, Humanities and socioeconomic Sciences, 2, 12 (2020)

3. N.B. Balashev, M.Kh. Barkinkhoeva, Economics and business: theory and practice, 56, 27 (2019)

4. N. Rozzani, I.S. Mohamed, S.N. Syed Yusuf, Research in International Business and Finance, 41, 20 (2017)

5. O.V. Zakharova, Problems of Economics, Finance and production management, 40, 14 (2017)

6. D.V. Dekhtyareva, O.P. Bondarchuk, Alley of science, 4, 185 (2018)

7. O.V. Kaurova, A.N. Maloletko, S.E. Avanesova, R.N. Almakaeva, Ya.S. Bazylev, E.I. Balalova, N.S. Belichko, A.V. Belyak, A.M. Bomko, E.S. Vasyutin, V.Yu. Dianova, V.E. Kosolapova, Yu.G. Kryukova, L.V. Matraeva, Report on $R \& D$ No. 0173100008619000031 dated August 27, 2019 (Ministry of Economic Development of the Russian Federation), Diagnostics of the system of established state microfinance organizations and development of a concept for the further development of a system 
for supporting small and medium-sized businesses through microfinance organizations (2019)

8. Order of the Ministry of Economic Development of the Russian Federation No. 745 dated November 9, 2020 "On approval of the concept of development of microfinance organizations "(2020)

9. I.V. Ershova, O.A. Tarasenko, Perm University Herald, Juridical Sciences, 39, 99 (2018)

10. K. Polyakov, L. Zhukova, Proceedings-2019. Actual problems of systems and software engineering (APSSE 2019), 12-14 November, 162 (2019) 